\title{
HOW POSITIVE AND NEGATIVE EMOTIONS INFLUENCE COGNITIVE PERFORMANCE IN SECONDARY SCHOOLS
}

\author{
Sonya Yakimova, Célia Maintenant, \& Anne Taillandier-Schmitt \\ Psychologie des âges de la vie et Adaptation (PAVeA) - EA 2114, Université de Tours (France)
}

\begin{abstract}
In the literature, less is known about the influence of emotions on cognitive performance at the crucial period of early- and mid-adolescence. Although the results are sometimes contradictory and contingent upon the perceived specific emotion in adulthood, the affective state is likely to influence cognition. Moreover, affective context is likely to impact deductive reasoning in youth and decision making. There is evidence that a negative affective experience will lead to poor cognitive performance. Therefore, experiencing a negative emotion (anger, anxiety, sadness...) should weaken the performance of students in cognitive tasks (e.g., reasoning or decision-making task). However, few studies have examined the impact of emotions on cognitive (not only academic) performance among adolescents and this is the objective of our research. After ethic committee agreement and parents' authorization, we asked 158 adolescents in secondary schools to respond to several questionnaires. More precisely, we proposed the French version of Differential Emotion Scale adapted for school context to measure the affective states. Syllogisms evaluated cognitive nonacademic performances. As results, we expected that negative emotions related to academic achievement would reduce performance in reasoning and positive emotions would improve it. There was only a significant effect for positive emotions on performance in reasoning Moreover, we tested the existence of differential effect of affective state on cognitive performance. according to age but it wasn't significant. The impacts of the results as well as perspectives of future research in relation with self-esteem, psychological disengagement and dropping out of school will be discussed. This research is funded by the French National Research Agency (Agence Nationale de la Recherche): ANR-18-CE28-0004-01.
\end{abstract}

Keywords: Affective states, emotions, cognitive performances.

\section{Introduction}

How emotions could play on cognitive performance in secondary schools? It is still too little known about the influence of affective states on cognitive performances at the crucial period of early- and mid-adolescence. In the literature concerning the adults the results can be contradictory and contingent upon the perceived specific emotion. The affective state is however likely to influence cognition (Blanchette \& Richards, 2010). According to Tricard, Maintenant and Pennequin (2018) the deductive reasoning of young people is influenced by emotions. Tricard and her colleagues (2018) as well as Fartoukh, Chanquoy and Piolat (2014) specify that a negative affective experience will lead to a poor cognitive performance. Thus, experiencing a negative affective state should weaken the performance of students in cognitive tasks like reasoning task. However, few studies have concretely examined the impact of affective state on cognitive and not only academic performance among adolescents. The objective of our research is to bring more information about that topic.

As our first hypothesis, we made the assumption that there was a significant correlation and a significant effect of the age on the cognitive performances: the cognitive performances should increase with age (H1). Second, we expected a significant correlation and a significant effect between the emotions about school and the cognitive performances: more the emotions about school are negative the lower should be the cognitive performances $(\mathrm{H} 2 \mathrm{a})$; more the emotions are positive the higher should be the cognitive performances $(\mathrm{H} 2 \mathrm{~b})$. Finally, we expected a significant interaction effect between the age and the emotions about school on the cognitive performances: more the emotions about school are negative and more the age is low the lower should be the cognitive performances (H3a); more the emotions are positive and more the age is high the higher should be the cognitive performances (H3b). 


\section{Methods}

\section{Participants}

158 students in secondary school (83 boys and 75 girls) participated in our research. They were 12 years-old on average (11-14 years, $S D=0.77)$. The most of them were in $6^{\text {th }}(11-12$ years old $)$ and in $5^{\text {th }}$ class (12-13 years old); two participants were in $4^{\text {th }}$ (13-14 years old) and two others in 3 th class (14-15 years old). $92 \%$ of the participants were French native speakers and the others were speaking French since more than five years.

\section{Procedure}

We obtained an ethic committee agreement for our study. We asked first school principals a permission to realize our study in their establishment and then we sent an authorization form to the parents to obtain a permission for the participation of their children. All participants completed the questionnaires at school, in group.

\section{Measures}

Our study contains as measures two questionnaires.

To measure negative and positive affective states related to academic situations, participants completed the 36 items of the French validation of the Differential Emotion Scale (DES) proposed by Ricard-St-Aubin, Philippe, Beaulieu-Pelletier and Lecours (2010) adapted firstly to the school context by Galand and Philippot (2005). Items were rated on a 5-point Likert scale ranging from 1 (Rarely or never) to 5 (Very often).

To measure cognitive nonacademic performances, we proposed 19 syllogisms. The participants needed to choose the fine answer between four different propositions of a possible conclusion of every syllogism. Our syllogisms had neutral emotional content and they were pretested about this in Tricard (2018). In order to Blanchette \& Richards (2010) the emotionality of the experiment's content has an effect on the cognitive performances and that is why we chose to include this type of syllogisms.

\section{Statistical analysis}

We analyzed our data within a Network (see Fonseca-Pedrero, 2018; Hevey, 2018) and SEM approaches framework. The Network analysis allowed us to explore the partial correlations and links between our different variables. The SEM analysis permitted us to test the impact of emotions on cognitive performances. Descriptive Statistics and Network analysis were done with JASP software (JASP Team, 2019) and SEM analysis was realized with AMOS software (Barnidge \& Gil de Zúñiga, 2017).

\section{Results}

We integrated our hypotheses in a model that we tested with SEM analysis. The fit of the model was very poor $\left(x^{2} / d f=228 ; \mathrm{p}=0.000 ; C F I=0.343 ; G F I=0.662 ; A G F I=-0.589 ; R M S E A=1.200\right)$ and many of path coefficient weren't significant. We explored then the zero-order correlation matrix which indicated that there were two significant correlations between the variables of our interest: a positive relation between Positives emotions and Cognitive performances $(r=.22, \mathrm{p}<.01)$ as well as a negative relation between Positives emotions and Age $(r=-.17, \mathrm{p}<.05)$. This step orientated our next analysis. We put the three variables from these two correlations to a network analysis (Figure 1). This time three partial correlations were significant: the relation between Age and Cognitive performances (H1), between Positives emotions and Age, and, between Positives emotions and Cognitive performances (H2b). Age and Cognitive performances were also negatively connected via Positives emotions. Thus, we transposed this model in SEM framework by orienting the effects of the variables in accordance with our hypotheses (e.g. a direct effect from Positives emotions and Cognitive performances, etc.) We obtained a good model fit but the effect of Age on Cognitive performances wasn't significant. We redid the analysis by omitting this link of the tested model (Figure 2) and the fit was very good $\left(x^{2} / d f=0.745 ; \mathrm{p}=0.338\right.$; $C F I=1.00 ; G F I=0.997 ; A G F I=0.981 ; R M S E A=0.000)$. The direct effect from Age to Positive emotions was significant $(\beta=0.22, \mathrm{p}<.05)$, with $\mathrm{R}^{2}=0.03$ for Positive emotions, as well as the direct effect from Positive emotions to Cognitive performances $(\beta=-0.17, \mathrm{p}<.05)$, with $\mathrm{R}^{2}=0.05$ for Cognitive performances. The indirect effect from Age to Cognitive performances was also significant $(\beta=-0.04, \mathrm{p}<.05)$. 
Figure 1. Network analysis.

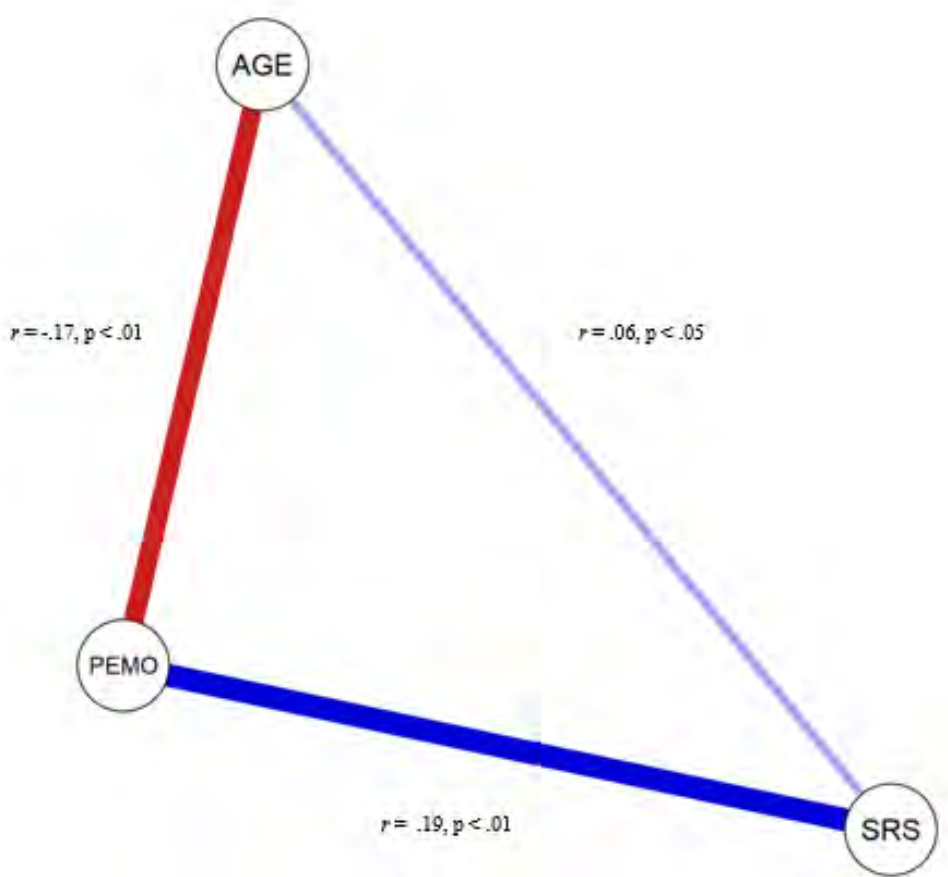

Legend: NEMO = Negative emotions; PEMO = Positive emotions; SRS = Syllogism reasoning score as a measure of Cognitive performances.

Figure 2. SEM analysis.

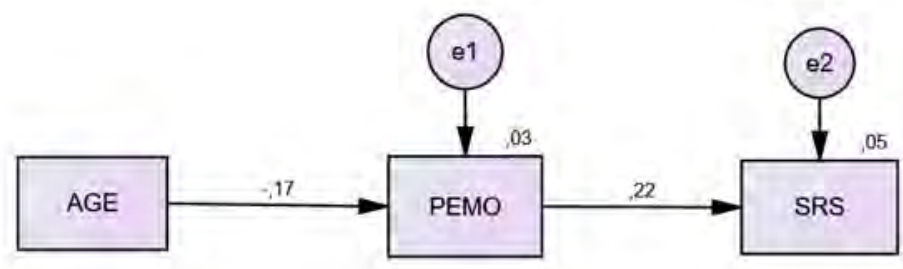

Legend: NEMO = Negative emotions; PEMO = Positive emotions; SRS = Syllogism reasoning score as a measure of Cognitive performances; e1 =residual variance of PEMO; e2 = residual variance of SRS.

\section{Discussion}

Our hypotheses were partially validated.

Concerning our first hypothesis, the age didn't directly affect the cognitive performances in our sample. The problem is that the majority of our participants was only 11-12 years old and this is not what we wished. It will be necessary to include more participants who are older (13-14 years old) for the next stage of our research. Thus, we can investigate if there is a difference, at least, between the group of 11-12 years old and the group of 13-14 years old pupils. The age had also a partial positive correlation and an indirect negative relation on the cognitive performances via the positive emotions in a network analysis. This negative indirect relation might have a suppression effect on the positive one and may explain why we didn't obtain a significant direct effect. These results give us un insight that the relationship between age and cognitive performance isn't probably unequivocal.

Concerning our second hypothesis, the positive emotions correlated with the performance on the reasoning test but not the negative ones. Consequently, only positive emotions affected the cognitive performance and in connection with our third hypothesis, this is without an interaction with the age of the participants. This is in line with the results of Radenhausen and Anker (1988) and more recently with the results of Caparos and Blanchette (2015) or Wang, Chen and Yue (2017) where positive emotions improve cognitive performances. What about negative emotions? Some researchers (e.g. Fiedler, 1990; Forgas, 1995; Royce \& Diamond, 1988) explain that reasoning tests are may be less constrained by 
emotions than other types of tests. It is also possible that pupils entered a state in which feelings do not influence the task performance like the state of flow (Czikszentmihalyi, Abuhamdeh, \& Nakamura, 2005). This could be valuable when both positive and negative emotions don't interfere with cognitive performances but, in our case, there were still a significant relation and a significant influence from positive emotions to cognitive performances. Melton (1995) showed that negative emotions could even improve cognitive performance. In our research we investigated the emotions on a global level as positive and negatives emotions. It will be interesting to study the link and the effect of emotions on cognitive performances on a specific level. May be some specific negative emotions could improve cognitive performances but other could do the opposite. Thus, this might explain why on global level there was no relation and no effect from negative emotions to cognitive performances. Concerning our third hypothesis, age had a negative indirect effect on cognitive performances mediated by positive emotions. It wasn't in our hypotheses but age had a positive direct effect on positive emotions. These results are in line with these obtained by Galand and Philippot (2005) but on a specific positive emotion level.

Thus, in future research, we must take also in account specific emotions and not only global emotions. We could also explore the influence of affective states on academic performances. Due to the risk of a vicious cycle between psychological disengagement and academic failure, better understanding of the link of emotions about school and academic performance appear like crucial. The understanding of this phenomenon added to the impact of self-esteem (a factor related to cognitive and academic performances, e.g. Simon \& Simon, 1975) on these variables would be important to investigate in order to avoid dropping out of school. It will be also interesting to explore the influence of motivation within a such a theoretical framework. As we know, the motivation is important in school learning (Nicholls $\&$ Thorkildsen, 1995). The perception of the school context by the students have an impact on their motivation (Ryan \& Patrick, 2001) and emotional experience at school (Galand \& Philippot, 2005). Thus, it is plausible that the emotions felt about school and motivation could influence academic performances (e.g. Valiente, Swanson \& Eisenberg, 2012).

This research is funded by the French National Research Agency (Agence Nationale de la Recherche): ANR-18-CE28-0004-01.

\section{References:}

Barnidge, M., \& Gil de Zúñiga, H. (2017). Amos (Software). J. Matthes, C.S. Davis and R.F. Potter, The International Encyclopedia of Communication Research Methods. doi:10.1002/9781118901731.iecrm0003

Blanchette, I., \& Richards, A. (2010). The Influence of Affect on Higher Level Cognition: A Review of Research on Interpretation, Judgement, Decision Making and Reasoning. Cognition \& Emotion, 24, 37-41. https://doi.org/10.1080/02699930903132496

Caparos,S., \& Blanchette, I. (2015). Affect et pensée logique : comment les émotions influencent notre raisonnement. Revue québécoise de psychologie, 36(1), pp.57-70.

Csikszentmihalyi, M., Abuhamdeh, S., \& Nakamura, J. (2005). Flow. In A. Elliot, \& C. Dweck (Eds.), Handbook of competence and motivation (pp. 598-608). New York: Guilford.

Fartoukh, M., Chanquoy, L., \& Piolat, A. (2014). Mood Induction in Children: Effect of the Affective Valence of a Text on Phonological Working Memory. Advances in Cognitive Psychology, 30, 10(3), 113-8. Doi: 10.4074/S0003503314002036.

Fiedler, K. (1990). Mood dependent selectivity in social cognition. European Review of Social Psychology, 1(1), 1-32.

Fonseca-Pedrero, E. (2018). Network analysis in psychology. Papeles Del Psicólogo, 39(1), 1-12. https://doi.org/10.23923/pap.psicol2018.2852

Forgas, J. P. (1995). Mood and judgment: The affect infusion model (AIM). Psychological Bulletin, 117(1), 39-66.

Galand, B., \& Philippot, P. (2005). L'école telle qu'ils la voient : validation d'une mesure des perceptions du contexte scolaire par les élèves du secondaire. Canadian Journal of Behavioural science, 37(2), 138-154.

Herry, C., Stromboni, M., Maintenant, C., \& Pennequin, V. (sept. 2015). Émotions et prise de décision à l'adolescence : "je prends le risque ou pas? J'écoute ce que me conseille mon corps... ». L'enfant entre rêve et réalité(s), 24ème congrès de l'Association Française des Psychologues de l'Education Nationnale, Angers, France.

Hevey, D. (2018). Network analysis: A brief overview and tutorial. Health Psychology and Behavioral Medicine, 6(1), 301-328. doi:10.1080/21642850.2018.1521283

JASP Team (2019). JASP (Version 0.11.1) [Computer software]. 
Melton, R. J. (1995). The role of positive affect in syllogism performance. Personality and Social Psychology Bulletin, 21, 788-794. DOI: 10.1177/0146167295218001

Nicholls, J. G., \& Thorkildsen, T. A. (Eds.) (1995). Reasons for learning: Expanding the conversation on student teacher collaboration. New York: Teachers College Press.

Radenhausen, R. A., \& Anker, J. M. (1988). Effects of depressed mood induction on reasoning performance. Perceptual and Motor Skills, 66, 855-860.

Ricard-St-Aubin, J. S., Philippe, F. L., Beaulieu-Pelletier, G., \& Lecours, S. (2010). Validation francophone de l'Échelle des émotions différentielles IV (EED-IV). Revue Européenne de Psychologie Appliquée/European Review of Applied Psychology, 60(1), 41-53. doi.org/10.1016/j.erap.2009.05.001

Royce, J. R., \& Diamond, S. R. (1980). A multifactor-systems dynamics theory of emotion cognitive interaction. Motivation and Emotion, 4, 263-298.

Ryan, A. M., \& Patrick, H. (2001). The classroom social environment and changes in adolescents' motivation and engagement during middle school. American Educational Research Journal, 38, 437-460

Simon, W.E., \& Simon, M.G. (1975). Self-esteem, intelligence and standardized academic achievement. Psychology in the Schools, 12, 97-99.

Tricard, E. (2018). Emotions et raisonnement : influence d'états émotionnels subjectifs sur les performances en raisonnement chez l'adolescent et le jeune adulte. [Emotions and reasoning: influence of subjective emotional states on reasoning performance in adolescents and young adults.] (unpublished doctoral dissertation). Tours, Université de Tours, France.

Tricard, E., Maintenant, C., \& Pennequin, V. (2018). Effet de la valence émotionnelle induite sur le raisonnement déductif chez les enfants de 9-10 ans. Neuropsychiatrie de l'enfance et de l'adolescence, 66(4), 203-209.

Valiente, C., Swanson, J., \& Eisenberg, N. (2012). Linking Students' Emotions and Academic Achievement: When and Why Emotions Matter. Child Development Perspectives, 6(2), 129-135. https://doi.org/10.1111/j.1750-8606.2011.00192.x

Wang,Y., Chen,J., \& Yue,Z. (2017). Positive Emotion Facilitates Cognitive Flexibility: An fMRI Study. Frontiers in Psychology, 8, 1-11. doi: 10.3389/fpsyg.2017.01832 